\title{
Pilsicainide-Induced Coronary Vasospasm in a Patient With Brugada-Type Electrocardiogram A Case Report
}

\author{
Ayumi Goda, MD*,**; Takeshi Yamashita, MD*; Takeshi Kato, MD*; Akira Koike, MD*; \\ Kouichi Sagara, MD*; Hajime Kirigaya, MD*; Haruki Itoh, MD*; \\ Tadanori Aizawa, MD*; Long-Tai Fu, MD*
}

\begin{abstract}
A 65-year-old man with Brugada-type electrocardiogram (ECG) was admitted to our hospital for chest pain, palpitation and faintness. In the cardiac electrophysiological study, no ventricular tachyarrthymia was induced either at baseline or after pilsicainide $(50 \mathrm{mg}$ ) infusion. Intravenous administration of pilsicainide exaggerated ST-segment elevation in $\mathrm{V}_{1-4}$ and converted it to the coved type in $\mathrm{V}_{1}$, accompanied by severe chest pain. Coronary angiography revealed the vasospasm of the right coronary artery was induced by pilsicainide, not by ergonovine. This is the first case report of coronary vasospasm induced by a pure sodium channel blocker in a patient with Brugada-type ECG. (Circ J 2005; 69: 858-860)
\end{abstract}

Key Words: Brugada-type ECG; Coronary spasm; Pilsicainide

I

n 1992, Brugada and Brugada reported 8 patients with sudden cardiac death characterized by right bundle branch block and persistent ST-segment elevation in the right precordial leads! Recently, to unmask or augment the ST-segment elevation, sodium channel blockers have been reported useful to identify the Brugada syndrome or the Brugada-type electrocardiogram (ECG)? We present a rare case with a complication of coronary vasospasm induced by one of sodium channel blockers.

\section{Case Report}

A 65-year-old man was admitted to our hospital complaining of chest pain and palpitation in January 2004. He had been followed-up in another hospital with diagnosis of hyperlipidemia and premature ventricular complexes, and prescribed flecainide for the control of the arrthymia for 1 year. Recently, the patient had often felt palpitation and faintness with some kind of a vague chest discomfort.

On admission, the ECG showed sinus rhythm with Brugada-type QRST complexes (saddle back type) with ST-segment elevation in V1 and V2 (Fig 1). His chest discomfort persisted for approximately $12 \mathrm{~h}$, and was accompanied by neither elevation of cardiac enzymes nor the left ventricular systolic dysfunction in the ultrasonic echocardiography and improved spontaneously. Even after oral flecainide was stopped, the ECG still showed the same saddle back type ST-segment elevation as before with frequent chest pain and palpitations after meals. The inhospital ECG monitoring revealed that his chest discomfort with palpitations was always accompanied by ventricular

(Received June 18, 2004; revised manuscript received January 13, 2005; accepted January 20, 2005)

*The Cardiovascular Institute, **Department of Cardiovascular Medicine, Tokyo Medical and Dental University, Tokyo, Japan

Mailing address: Ayumi Goda, MD, The Cardiovascular Institute, 73-10 Roppongi, Minato-ku, Tokyo 106-0032, Japan. E-mail: goda@ cvi.or.jp premature beats, without further changes in ST-T waves in sinus beats, thereby being considered to result from the extrasystoles.

The ST-segment elevation in $\mathrm{V}_{1}$ and $\mathrm{V}_{2}$ in his ECG showed no circadian variation and no relationship with his chest discomfort and faintness. To stratify a risk of the patient, the cardiac electrophysiological study was performed. Neither sustained ventricular tachycardia nor ventricular fibrillation was induced by ventricular stimulation up to the triple extrastimuli either at baseline or after pilsicainide $(50 \mathrm{mg}$ ) infusion. However, after intravenous administration of pilsicainide, he began to complain of strangling chest pain, which was of a different kind as he had previously felt, and the ECG showed exaggerated STsegment elevation in $\mathrm{V}_{1-4}$ and conversion to the coved type in $\mathrm{V}_{1}$ and ST-segment depression in II, III, $\mathrm{aVF}$ (Fig 2). His chest pain improved after intravenous administration of nitroglycerin with the prompt recovery of the ST-segment elevation.

Coronary angiography was also performed to determine the cause of the chest pain induced by pilsicainide. No significant organic coronary stenosis was observed at baseline. After intravenous administration of pilsicainide $(50 \mathrm{mg})$, the right coronary artery showed $90 \%$ stenosis in its proximal site (Fig 3). However, he did not feel any chest pain, which was possibly as a result of day-to-day variation of pilsicainide-induced vasospasm. After the spontaneous relief of the spasm, intracoronary ergonovine $(0.04 \mathrm{mg})$ was administered, but no vasospasm was induced. In addition, no vasospasm was induced in the left coronary artery, either by pilsicainide or by ergonovine.

\section{Discussion}

Brugada syndrome is characterized by ST-segment elevation in $\mathrm{V}_{1-3}$ with a right bundle branch block pattern and nocturnal sudden cardiac death presumably caused by ventricular fibrillation. The syndrome has been, in part, 


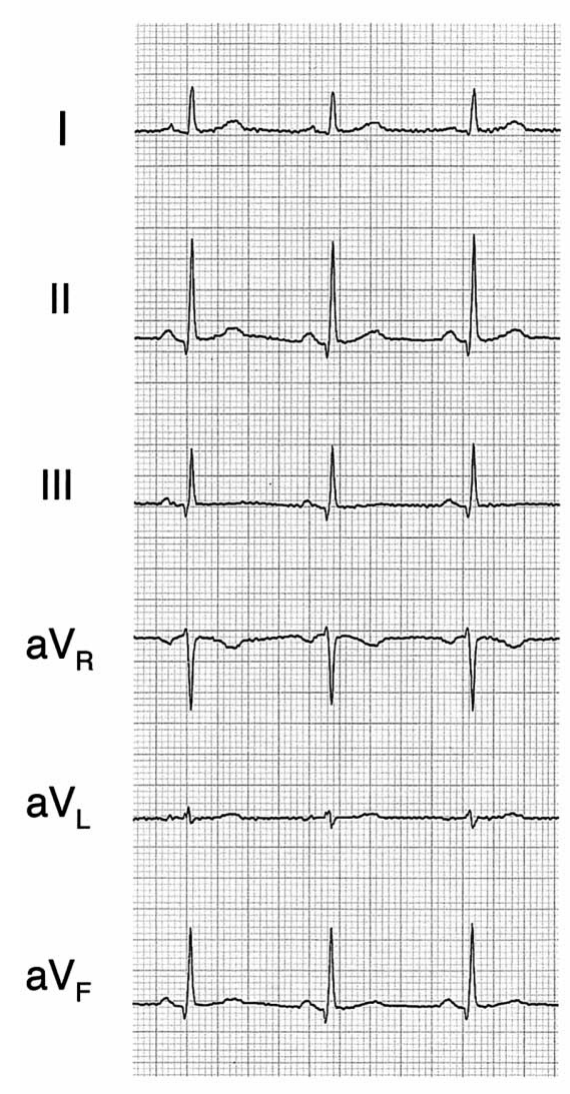

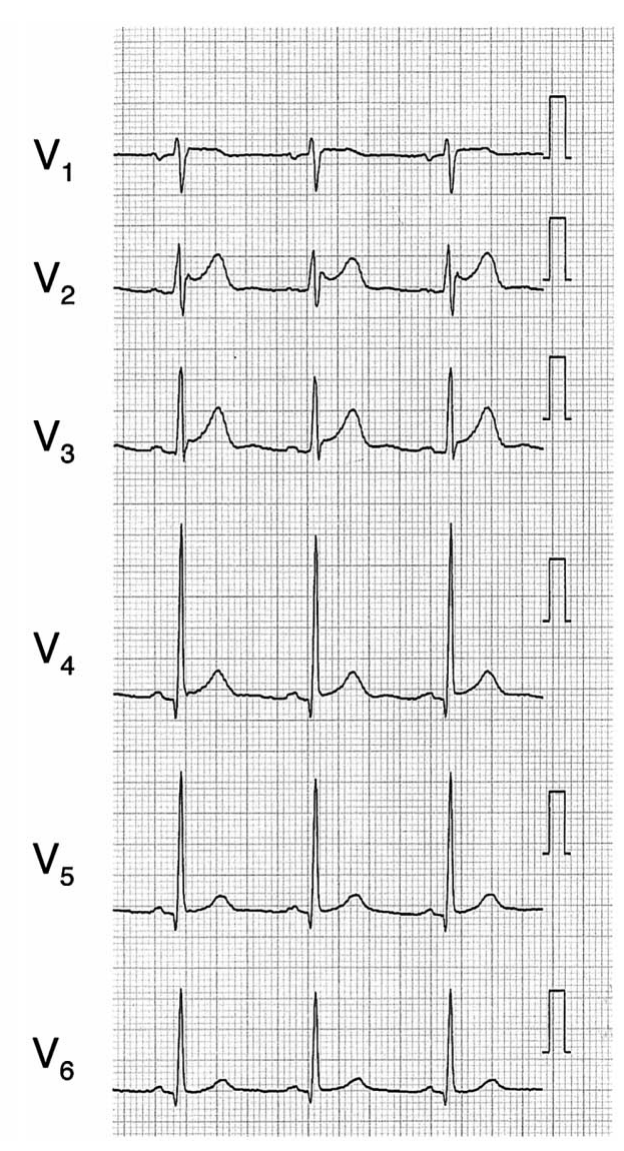

Fig 1. The electrocardiogram on admission, showing sinus rhythm with Brugada-type QRST complexes (saddle back type) and ST-segment elevation in $\mathrm{V}_{1}$ and $\mathrm{V}_{2}$.
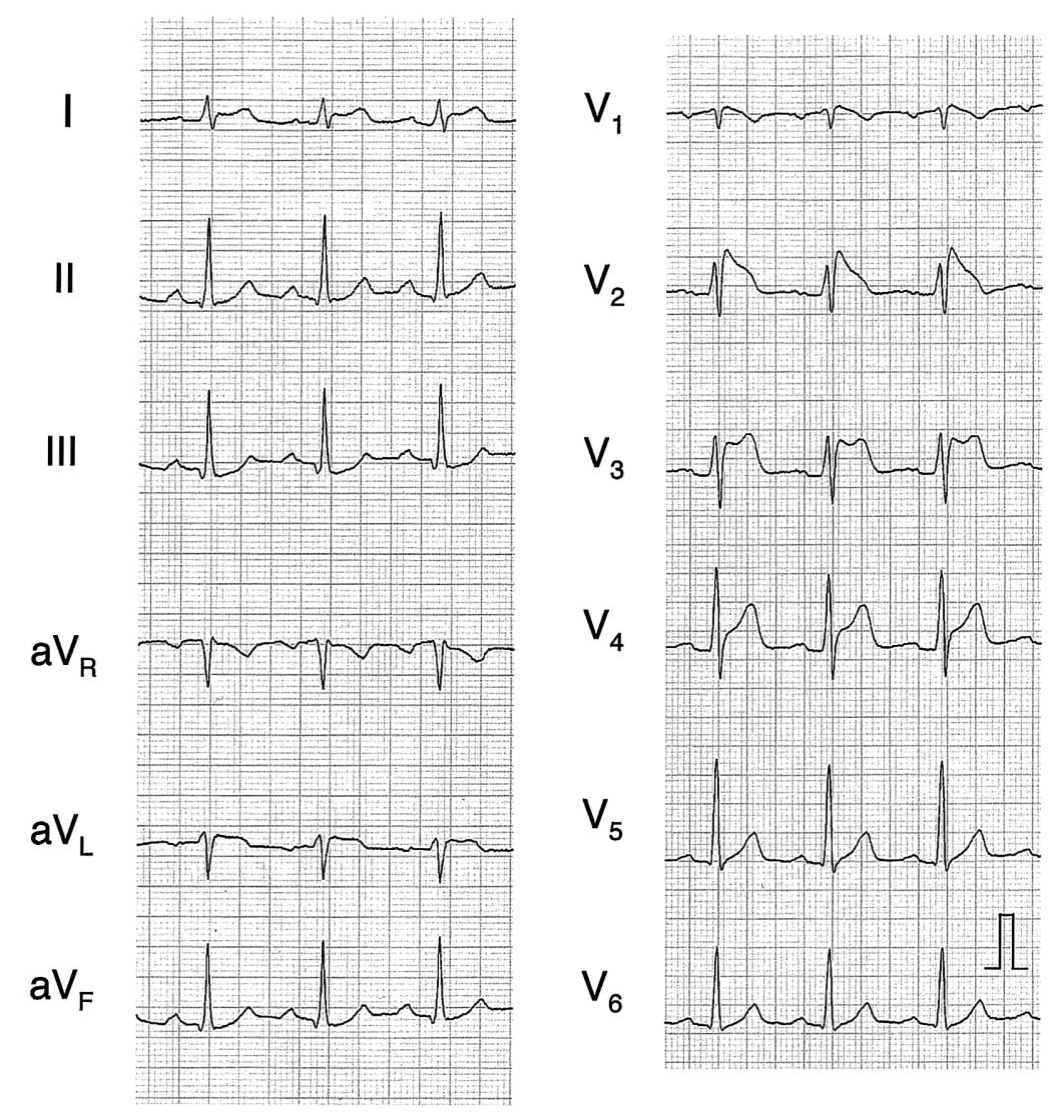

Fig 2. The electrocardiogram after intravenous administration of pilsicainide $(50 \mathrm{mg})$, showing exaggerated ST-segment elevation in $\mathrm{V}_{1-4}$ and conversion to the coved type in $\mathrm{V}_{1}$ and ST-segment depression in II, III, aVF. 


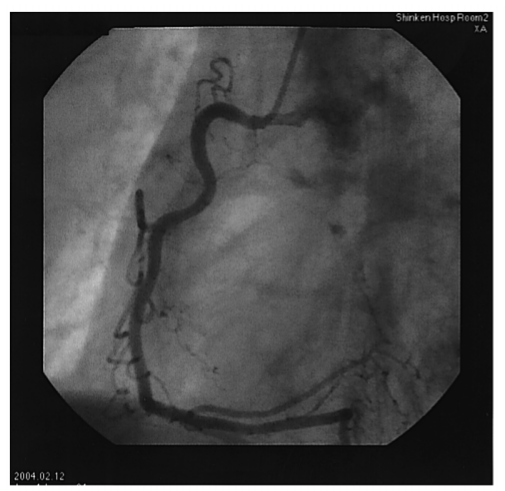

Control

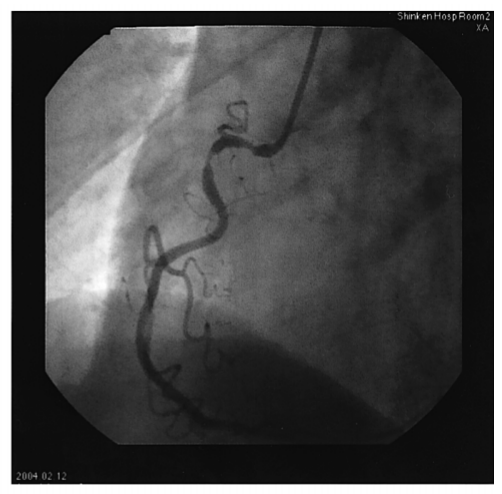

Pilsicainide 50mg
Fig 3. The coronary angiograms after intravenous administration of pilsicainide $(50 \mathrm{mg})$, showing $90 \%$ stenosis in the proximal site of the right coronary artery distant from the tip of the catheter. In this case, ergonovine test was negative. linked to mutations in $S C N 5 A$, the gene encoding for thea subunit of the cardiac sodium channel? The ST-segment elevation and the arrthymia in patients with Brugada syndrome have been explained by abnormal shortening of the epicardial action potential duration and phase 2 re-entry at the right ventricle. 4 A sodium channel blocker has been reported to unmask or augment the ST-segment elevation. The mechanisms have been said that a strong sodium channel block facilitates the loss of the right ventricular epicardial action dome (plateau phase) by altering the balance of current at the end of phase 1 of the action potential from inward to outward.

Challenges of sodium channel blockers such as pilsicainide, which is classified as a class Ic antiarrhythmic drug and has been shown to have a pure sodium channel-blocking effect, are frequently used to identify the Brugada syndrome or the Brugada-type ECG. In patients with saddle back type ECG, conversion to a coved type ECG is also considered as a positive study. However, the specificity of the challenge test for uncovering patients at risk for sudden death has been an issue of concern5-7

After intravenous administration of pilsicainide, the patient's ECG showed exaggerated ST-segment elevation and conversion to the coved type in the right precordial leads. However, he began to complain of chest pain, which actually resulted from the sodium channel blocker-induced vasospasm in the proximal site of the right coronary artery. Although the ST-segment elevation in $\mathrm{V}_{1-4}$ might be induced by the sodium channel blocking effect, ECG changes could be affected also by the spasm-induced myocardial ischemia. The ST-segment depression in II, III, $\mathrm{aVF}$, although not remarkable, could be attributed possibly to vasospasm of the right coronary artery. In this case, ECG changes could be complex, resulting from the mixture of these 2 mechanisms. Therefore, we could not precisely correlate the multiple ECG changes to the sodium channel blocking effect and the spasm-induced myocardial ischemia. Surprisingly, in the current case, vasospasm was induced only by pilsicainide, not by ergonovine. This is the first case report of coronary vasospasm induced by a pure sodium channel blocker, simultaneously leading to the modification of Brugada-type ECG.

There are some case reports with vasospastic angina, which is inducible by administration of acetylcholine, frequently coexisted with Brugada syndrome and Brugadatype ECG ${ }^{8-10}$ Conversely, no previous reports have described coronary vasospasm induced by administration of a sodium channel blocker, which would be a very unlikely observation because sodium channels are not believed to exist in vascular smooth muscle cells nor in endothelial cells. Therefore, our case raised several new possibilities that require further studies in the future. They include abnormal expression of sodium channels in vasculature and/or indirect release of vasoconstrictor agents, such as thromboxane A2, angiotensin II, vasopressin, noradrenaline, and serotonin induced by pilsicainide.

In conclusion, applying the challenge test using sodium channel blockers in Brugada-type ECG, we should keep in mind that coronary vasospasm could be induced by pilsicainide, which might modify Brugada-type ECG, as seen in the present case. Moreover, this case would raise the new risk of this challenge test, unpredictable vasospasm by pilsicainide, in Brugada-type ECG.

\section{References}

1. Brugada P, Brugada J. Right bundle branch block, persistent ST segment elevation and sudden cardiac death: A distinct clinical and electrocardiographic syndrome: A multicenter report. J Am Coll Cardiol 1992; 20: 1391-1396.

2. Brugada R, Brugada J, Antzelevitch C, Kirsch GE, Potenza D, Towbin JA, et al. Sodium channel blockers identify risk for sudden death in patients with ST-segment elevation and right bundle branch block but structurally normal hearts. Circulation 2000; 101: 510515.

3. Chen Q, Kirsch GE, Zhang D, Brugada R, Brugada J, Brugada P, et al. Genetic basis and molecular mechanisms for idiopathic ventricular fibrillation. Nature 1998; 392: 293-296.

4. Yan GX, Antzelevitch C. Cellular basis for the Brugada syndrome and other mechanism of arrhythmogenesis associated with ST-segment elevation. Circulation 1999; 100: 1660-1666.

5. Widle AAM, Antzelevitch C, Borggrefe M, Brugada J, Brugada R, Brugada P, et al. Proposed diagnostic criteria for Brugada syndrome: Consensus report. Circulation 2002; 106: 2514-2519.

6. Morita H, Morita-Takenaka S, Nagase S, Banba K, Nishii N, Tani Y, et al. Ventricular arrhythmia induced by sodium channel blocker in patients with Brugada syndrome. J Am Coll Cardiol 2003; 42: 16241631.

7. Morita H, Morita-Takenaka S, Nagase S, Fukushima-Kusano K, Kobayashi M, Nagase S, et al. Risk stratification for asymptomatic patients with Brugada syndrome-Prediction of induction of ventricular fibrillation by noninvasive methods. Circ J 2003; 67: 312-316.

8. Chinushi Y, Kuroe M, Toida T, Aizawa Y. Class 1 antiarrhythmic drug and coronary vasospasm-induced $\mathrm{T}$ wave alternans and ventricular tachyarrhythmia in a patient with Brugada syndrome and vasospastic angina. J Cardiovasc Electrophysiol 2002; 13: 191-194.

9. Chinushi M, Kuroe Y, Ito E, Tagawa M, Aizawa Y. Vasospastic angina accompanied by Brugada-type electrocardiographic abnormalities. J Cardiovasc Electrophysiol 2001; 12: 108-111.

10. Itoh E, Suzuki K, Tanabe Y. A case of vasospastic angina presenting Brugada-type ECG abnormalities. Jpn Circ J 1999; 63: 493-495. 